NBER WORKING PAPER SERIES

\title{
RISK AVERSION AND DETERMINANTS \\ OF STOCK MARKET BEHAVIOR
}

Robert S. Pindyck

Working Paper No. 1921

\author{
NATIONAL BUREAU OF ECONOMIC RESEARCH \\ 1050 Massachusetts Avenue \\ Cambridge, MA 02138 \\ May 1986
}

\footnotetext{
This paper was written while the author was Visiting Professor and Fellow, Institute of Advanced Studies, Tel-Aviv University. The research reported here in was supported by the National Science Foundation under Grant No. SES-B318990. The author is grateful to Martin Feldstein and James Poterba for providing updated calculations of the pretax rate of return, to Ofer Argov and Eric Moran for their excellent research assistance, and to 0livier Blanchard, Benjamin Friedman, Leonardo Leiderman, James Poterba, Robert Shiller, and Lawrence Summers for helpful comments and suggestions. The research reported here is part of the NBER's research program in Financial Markets and Monetary Economics. Any opinions expressed are those of the author and not those of the National Bureau of Economic Research.
} 
Working Paper \#1921

May 1986

Risk Aversion and Determinants of Stock Market Behavior

\section{ABSTRACT}

A simple model of equity pricing is developed to address two related questions. First, to what extent can unanticipated changes in such "fundamental" variables as profitability, real interest rates, inflation, and the variance of returns account for the observed behavior of the stock market? Second, how risk averse are investors in the aggregate? We find that the pretax profit rate and the variance of returns are both significant explanators of the market, and interest rates somewhat less so. Estimates of the index of relative risk aversion are obtained that put that parameter in the range of 3 to 4.

Robert S. Pindyck

Sloan School of Management

M.I.T.

50 Memorial Drive

Cambridge, MA 02139 


\section{Introduction.}

This paper addresses two related questions. First, to what extent can the behavior of the stock market be explained by observed changes in such "fundamental" variables as profitability, inflation, real interest rates, and the variance of stock returns - variables that affect the expected real after-tax flow of dividends to investors, andlor the: rate at which that flow is discounted? Note that this question is in noway in conflict with the notion that the market follows a random walk. We are simply asking whether the "suprises" that have been observed in the market can be explained in part by unpredicted changes in economic variables, and in a manner consistent with theory.

The answer to this first question is in part dependent on the answer to the second: How risk averse are investors in the aggregate? There is litle concensus as to the index of relative risk aversion for U.s. investors in the aggregate, with recent estimates ranging from 0.3 to numbers in excess of 6.2 Knowledge of this parameter is important for our understanding of the structure of asset demands. For example, several recent studies have used aggregate asset demand models to determine the effects of government budget deficits or to explain the behavior of interest rates, and in each case a number was chosen for the index of risk aversion. 2 But the results

\footnotetext{
'Consumption-based estimates are usually below 1; for example, Hansen and Singleton (1983) and Mankiw, Rotemberg, and Summers (1985) obtained estimates in the $r$ ange of .3 to 1.0 . Asset demand studies have yielded higher estimates; the papers by Friend and Blume (1975), Friend and Hasbrouck (1982), and Grossman and Shiller (1981) support estimates in the range of 2 to 6 .

In his study of crowding out, Friedman (1985) uses a value of 4 for the index of risk aversion. In a similar study, Frankel (1983) attempts to estimate this parameter, but after obtaining an estimate in excess of 100, he set the value at 2. Bodie, Kane, and McDonald (1983) explain the behavior of long-term interest rates in terms of changing asset return covariances; they also use a value of 2 .
} 
of such studies can be sensitive to this choice. This paper provides new estimates of this parameter.

A number of earlier studies have sought to explain broad movements in stock prices by changes in economic variables. For example, the papers by Modigliani and Cohn (1979), Fama (1981), Feldstein (1980a,b), and Summers (1981) attribute (for different reasons) the secular decline in the market between 1965 and 1980 to increased inflation. A paper of mine (1984), argues that this decline is better explained by increases in the variance of equity returns, and by reductions in the expected return on capital. Gordon (1983) obtained similar results; he used a general model of share valuation under inflation to show that reduced profitability and a higher risk premium, rather than increased inflation, explain the market decline. The role of a changing risk premium is also supported by the work of Hasbrouck (1984a;b), who finds that ex ante measures of uncertainty over real economic activity (obtained from survey data) are a significant determinant of stock returns, and are meaningfully related to the expost variance of those returns, and French, Schwert, and Stambaugh (1985), who find that unexpected returns are negatively related to unexpected changes in volatility.

This paper develops and tests a structural model that explains stock returns in terms of changes in several fundamental variables. The model relates these variables to the basic determinants of stock prices -- the expected real after-tax flow of dividends to investors, and the discount rate investors use to discount this flow. This involves modelling the tax

3However these statistical studies are not based on structural madels of stock price determination. Similarly, Chen, Roll and Ross (1985) use non-structural regressions to examine the ability of a number of economic variables to explain stock returns. 
system and the financial structure of firms, as is done in some of the studies cited above. Also, as Poterba and Summers (1985) have pointed out, the effects of changes in explanatory variables will depend in part on the persistence of those changes.4 For example, if changes in interest rates, etc. are short-lived, they should have only a small effect on investors' asset demands, and on asset prices. Finally, the effects of changes in explanatory variables will depend on the degree of investor risk aversion. This last parameter is particularly important, and an estimate of its value is essential for any explanation of market behavior.

Our approach assumes constant relative risk aversion, so that changes in stock prices can be related to unanticipated changes in each of several different economic variables, with elasticities that all depend on the degree of risk aversion. Specifically, the price of equity is related to four explanatory variables - the pretax profit rate, the real short-term interest rate, the rate of inflation, and the variance of equity returns that affect the expected flow of dividends and/or the rate at which that flow is discounted by investors, as well as tax and financial paraneters, and the index of risk aversion. Changes in the price of equity depend in part on changes in these explanatory variables, and on the persistence of those changes. As in Foterba and summers (1985), persistence effects are modelled by describing the explanatory variables as AR(1) processes.

By linearizing the expression for the price of equity around the mean values of the explanatory variables, a set of regression equations with

apoterba and Summers make this point in reference to the volatility of the stock market. It has long been recognized that the volatility of equity returns has changed over time; see officer (1973), Black (1976), and Merton $(1980)$. Poterba and summers argue that these changes are short-1ived, and thus should have had only a small effect on stock prices. 
cross-equation parameter constraints is obtained. The first equation relates changes in the price of equity to innovations in the explanatory variables. The remaining equations are the AR(1) processes for the explanatory variables. Each constraint ties an elasticity in the first equation to a corresponding AR(1) parameter, and to the index of risk,aversion. Estimating this system yields values for the elasticities, and for the index of risk aversion. Also the underlying theory is completely summarized by the constraints, and can be tested by testing the constraints.

The empirical results can be summarized as follows. First, the response of stock returns to changes in profitability, interest rates, inflation, and the variance of returns is consistent with an index of relative risk aversion of about 3 or 4. This is in the mid-range, of estimates obtained from earlier asset demand studies, but at the high end of the range of numbers used in applications of asset demand models (see Footnotes 1 and 2). Second, estimates of the model support the argument that changes in the volatility of returns play a significant role in explaining stock price movements. Although changes in volatility have not been very persistent during the post-Har period (as Poterba and summers have demonstrated), the magnitudes of those changes have been large enough, and the index of risk aversion high enough, to make their effects significant. Changes in the pretax profit rate and the real interest rate are also significant explanators of stock price movements. However, inflation is not significant, in keeping with the findings of Gordon (1983) and Hasbrouck (1984a,b).

The next section lays out the model. The data and issues of estimation are discussed in Section 3 . Statistical results are presented and discussed in section 4, and section 5 contains some concluding remarks. 


\section{The Madel.}

As in my earlier paper (1984), portfolio choice is limited in this model to two assets, stocks and short-term nominal bonds. Here l treat the instantaneous inflation rate as deterministic, so that bonds are risk-free, with a net real return given by:

$$
\varrho_{0}=(1-\theta) R-\pi
$$

where $R$ and $\pi$ are the nominal interest rate and inflation rate, and $\theta$ is the personal tax rate on interest and dividends. (Parameters and symbol definitions are summarized in Table 1 of Section 3.)

The total gross return to investors from holding stocks has two components, capital gains and dividends. Let $s$, be the net real return to investors from stocks. Then the expected net real return is given by:

$$
E_{t}\left(\xi_{*}\right)=\left(1-\theta_{t}\right)\left[E_{t}\left(P_{t} \frac{1}{1}\right)-P_{t}-E_{-}\right]+(1-\theta) D_{t} / P_{t}-\theta_{c} \pi
$$

where $P$ is the price of equity, $D$ is the pretax flow of dividends, and $\theta_{e}$ is the effective tax rate on capital gains.

Assuming constant relative risk aversion, the risk premium can be approvimated by:

$$
E_{t}\left(s_{s}\right)-s_{b}=\gamma \operatorname{Var}\left(\xi_{s}\right)
$$

where $y$ is the aggregate index of relative risk aversion. (For heterogeneous investors, $\gamma=1 / \Sigma_{1}\left(w_{1} / \gamma_{1}\right)$, where $\gamma_{1}$ is the index for investor $i$, and the weight $w_{1}$ is based on wealth.) Now let $\sigma^{2}$ be the variance of pretax

Shis is an approximation, even for constant relative risk aversion. If the state variables $\alpha, r$, etc. move stochastically over time, as they are assumed to in this model, the risk premium will also depend on a set of hedging demands, and (3) will not hold exactly. See Merton (1973). 
real stock returns, and $d$ be the average ratio of dividends to net earnings. Then the variance of the after-tax real return is $[(1-\theta) d+$ $\left.\left(1-\theta_{c}\right)(1-d)\right]^{2} \sigma^{2}$, and

$$
E_{t}\left(\xi_{s}\right)-\xi_{b}=\gamma\left[(1-\theta) d+\left(1-\theta_{c}\right)(1-d)\right]^{2} \sigma^{2}
$$

To simplify the model, I take the real interest rate, denoted by $r_{t}$, as exogenous, and write $R_{t}=r_{t}+\pi_{t}$, so that $d R_{t} / d \pi_{t}=1$. Then eqns. (1) to (4) can be combined to yield the following equation relating the aftertax real excess return to the variance of the pretax real return, of:

$$
\left(P_{t+1}-P_{t}\right) / P_{t}+\phi_{1} D_{t} / P_{t}-\phi_{1} r_{t}+\left(1-p_{1}\right) \pi_{t}=\gamma_{2} \sigma_{t}^{2}+\varepsilon_{t}
$$

Here $E_{t}=\left[P_{t+1}-E_{t}\left(P_{t+2}\right)\right] / P_{t}$ is an expectational error, $\phi_{2}=(1-\theta) /\left(1-\theta_{c}\right)$, and $\phi_{2}=\left[(1-\theta) d+\left(1-\theta_{c}\right)(1-d)\right] 2 /\left(1-\theta_{c}\right)$. Sinced $\phi_{1}, \phi_{2}$, and a series for oz can all be calculated, with a suitable stochastic specification eqn. (5) can be used to obtain a preliminary estimate of $y$. This is done in section 4 .

The expectational error $\varepsilon_{t}$ in eqn. (5) consists in part of the effects of unanticipated changes in the explanatory variables, effects which depend in part on the index of risk aversion $\gamma$. We therefore want to "explain" this portion of $\varepsilon_{t}$. Doing so will reveal information about the relative importance of the various explanatory variables in affecting stock prices, and will enable us to obtain more efficient estimates of $y$.

We proceed by obtaining an expression for the expected flow of dividends: First, note that the firm's expected real net earnings per dollar of equity, $E_{t}\left(\psi_{-}\right)$, can be written as:

$$
(1-b) E_{t}\left(\psi_{s}\right)=\left(1-\tau_{e}\right) \alpha_{t}-\left(1-\tau_{s}\right) b\left(r_{t}+\pi_{t}\right)+(b-\lambda) \pi_{t}
$$

where $\alpha$ is the expected pretax rate of profit lthe expected real gross 
return on (apital), b is the average rate of borrowing per dollar of capital, $\tau_{-}$and $\tau_{\text {. }}$ are respectively the effective and statutory corporate tax rates, and $\lambda$ is a measure of the reduction in real net earnings through the tan effect of inflation. We can thus write the following expression for the pretax flow of dividends to investors:

$$
D_{t}=-\frac{d}{(1-b)}\left[\left(1-\tau_{e}\right) a_{t}-\left(1-\tau_{s}\right) b\left(r_{t}+\pi_{t}\right)+(b-\lambda) \pi_{t}\right]
$$

Now, utilizing this expression for $D_{t}$, eqn. (5) has the following solution for the price of equity:

$$
F_{t}=E_{t} \sum_{s=0}^{\infty}\left[\frac{\phi_{3} \alpha_{t+j}-\phi_{4}{ }_{t+j}-\phi_{5} \pi_{t+j}}{\prod_{t \rightarrow 0}\left(1+\phi_{1} r_{t+i}-\left(1-\phi_{1}\right) \pi_{t+i}+\phi_{2} \sigma_{t+i}^{2}\right)}\right]
$$

where $\phi_{3}=d\left(1-\tau_{0}\right) /(1-b), \phi_{4}=\left(1-\tau_{-}\right) b d /(1-b)$, and $\phi_{5}=\phi_{4}+(\lambda-b) d /(1-b)$.

Eqn. (8) expresses the price of equity in terms of current and future values of the explanatory variables $\alpha, r, \pi$, and $\sigma^{2}$. Changes in $p$ will result from changes in the current values of these variables, and changes in their expected future values. To describe expectations, I follow Poterba and Summers and treat these variables as AR(1) processes, i.e.

$$
\begin{aligned}
& \alpha_{t}=e_{\alpha 0}+p_{\alpha} \alpha_{t-1}+v_{1 t} \\
& r_{t}=e_{r 0}+e_{r} r_{t-1}+v_{2 t}
\end{aligned}
$$

- The effective tax rate is less than the 5 tatutory rate because of accelerated depreciation and the investment tax credit. Nominal interest payments, $b(r+\pi)$, are deductible at the statutory rate, and since inflation reduces the real value of the firm's debt, the after-tax cost of borrowing is $(1-\tau) b(r+\pi)-b \pi$. Finally, as Feldstein (1980b) has shown, because the value of depreciation allowances is based on original cost, inflation reduces their real value and increases real taxable profits; I use Feldstein's linear approximation that a $1 \%$ increase in the price level reduces net profits by $\lambda$. For a more detailed discussion, see my 1984 paper. 


$$
\begin{aligned}
& \pi_{t}=\rho_{\pi 0}+\rho_{\pi} \pi_{t-1}+v_{3 t} \\
& \sigma_{t}^{2}=\rho_{\sigma 0}+\rho_{\sigma} \sigma_{t-1}^{2}+v_{4 t}
\end{aligned}
$$

where the error terms $v_{1}$ may be contemporaneously correlated.?

Now linearize eqn. (8) for $F_{t}$ around the mean values of the explanatory variables, $\bar{a}, \bar{r}, \bar{\pi}$, and $\bar{\sigma}^{2}$ :

$$
\begin{aligned}
P_{t}= & \sum_{s=0}^{\infty} \bar{D} / \Phi+\sum_{j=0}\left(\partial F_{t} / \partial \alpha_{t+j}\right)\left[E_{t}\left(\alpha_{t+j}\right)-\vec{a}_{t}\right]+ \\
& \sum_{t=0}^{\infty}\left(\partial P_{t} / \partial r_{t+j}\right)\left[E_{t}\left(r_{t+j}\right)-\bar{r}\right]+\sum_{s=0}\left(\partial P_{t} / \partial \pi_{t+j}\right)\left[E_{t}\left(\pi_{t+j}\right)-\bar{\pi}\right] \\
& +\sum_{j=0}\left(\partial P_{t} / \partial \sigma_{t+j}^{2}\right)\left[E_{t}\left(\sigma_{t+j}^{2}\right)-\bar{\sigma}^{2}\right]
\end{aligned}
$$

where $\bar{D} \equiv\left(\phi_{3} \bar{\alpha}-\phi_{4} \bar{r}-\phi_{5} \bar{\pi}\right)$ is the mean value of the after-tax dividend rate, $\pm \equiv 1+\phi_{1} \bar{r}+\left(1-\phi_{1}\right) \bar{\pi}+\phi_{2} \gamma^{-2}$ is the mean rate at which expected future dividends are discounted, and:

$$
\begin{aligned}
& \partial P_{t} / \partial a_{t+j}=d{ }^{-j-1} \\
& \partial F_{t} / \partial r_{t+j}=-4_{4}{ }^{-j-1}-D_{1} \sum_{k=0}^{\infty} x^{-k-j-2} \\
& \partial P_{t} / \partial \pi_{t+j}=-\phi_{4} \bar{\Phi}^{-j-1}-\left(\phi_{1}-1\right) \bar{D} \sum_{k=0}^{\infty} \Phi^{-k-j-2} \\
& \partial P_{t} / \partial \sigma_{t+j}^{2}=-\gamma \phi_{2} \bar{D} \sum_{k=0}^{\infty} \bar{s}^{-k-j-2} \text {. }
\end{aligned}
$$

From the AR(1) equations (9a) - (9d) we have:

$$
\begin{aligned}
& E_{t}\left(\alpha_{t+j}\right)-\bar{\alpha}=\rho_{\alpha}^{j}\left(\alpha_{t}-\bar{\alpha}\right), \\
& E_{t}\left(r_{t+j}\right)-\bar{r}=\rho_{r}^{j}\left(r_{t}-\bar{r}\right), \text { etc. }
\end{aligned}
$$

Clearly one could do better. For example, Hendershott (1984) shows that changes in 6-month T-bill rates can be partly predicted by unanticipated changes in expected inflation, and in the growth of industrial production and base money. But the $A R(1)$ specification provides a reasonable "first-order" forecast, and greatly simplifies the model. 
Substituting into eqn. (10), and noting that $\sum_{k=0} \Phi^{-k-j-2}=\Phi^{-j-1} /(x-1)$, we obtain the following equation that relates $P_{t}$ to the current values of $a_{t}$, $r_{t}, \pi_{t}$, and $\sigma_{t}^{2}$ :

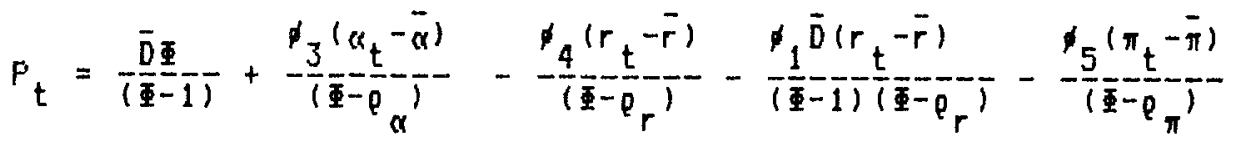

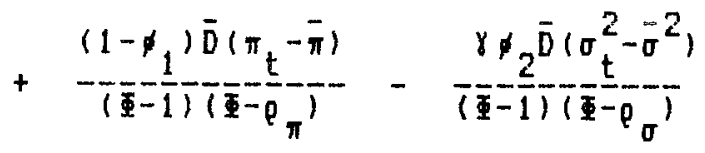

The first term on the RHS of (11) is the mean price, which we denote by $\bar{F}$. The remaining terms describe deviations of $p$ from $\bar{P}$ in response to deviations of the explanatory variables from their mean values.) Eqn. (11) can be used to relate the expected next-period price to the expected nextperiod values of the explanatory variables. The latter are given by eqns. (9a) - (9d); 1.e. $E_{t}\left(\alpha_{t+1}\right)=$ poo + palt, etc. The resulting expression for the expected next-period price can in turn be substituted for $E_{t}\left(P_{t+2}\right)$ in the expectational error at of eqn. (5). Making this substitution and approximating $\Delta P / P$ by $\Delta l o g P$ yields:

$$
\begin{aligned}
\Delta \log P_{t} & +\phi_{1} D_{t-1} / p_{t-1}-\phi_{1} r_{t-1}+\left(1-\phi_{1}\right) \pi_{t-1}=\beta_{2} \sigma_{t-1}^{2} \\
& -\left(\eta_{\alpha} \rho_{\alpha}{ }^{0}+\eta_{r} \rho_{r} 0\right. \\
& \left.+\eta_{\pi} \rho_{\pi 0}+\eta_{\sigma} \rho_{\sigma 0}\right)+\eta_{\alpha}\left(\alpha_{t}-\rho_{\alpha} \alpha_{t-1}\right) \\
& +\eta_{r}\left(r_{t}-\rho_{r} r_{t-1}\right)+\eta_{\pi}\left(\pi_{t}-\rho_{\pi} \pi_{t-1}\right)+\eta_{\sigma}\left(\sigma_{t}^{2}-\rho_{\sigma} \sigma_{t-1}^{2}\right)
\end{aligned}
$$

where the elasticities $\eta_{a}, \eta_{r}$, etc. are taken around the mean price $\bar{P}$ and must satisfy the following constraints:

$$
\begin{aligned}
& \eta_{\alpha}=\phi_{3}(\Phi-1) / \bar{D} \Phi\left(\Phi-\theta_{\alpha}\right) \\
& \eta_{r}=-\phi_{1} / \Phi\left(\Phi-\rho_{r}\right)-\phi_{4}(\Phi-1) / \bar{D} \Phi\left(\Phi-\rho_{r}\right)
\end{aligned}
$$




$$
\begin{aligned}
& \eta_{\pi}=\left(1-\phi_{1}\right) / \Phi\left(\Phi-\varphi_{\pi}\right)-\phi_{5}(\Phi-1) / \bar{D} \Phi\left(\Phi-\varphi_{\pi}\right) \\
& \eta_{\sigma}=-\gamma \phi_{2} / \Phi\left(\Phi-\rho_{0}\right)
\end{aligned}
$$

Eqn. (12) together with eqns. (9a) - (9d) describe the dependence of stock prices on $\alpha t, r_{t}, \pi t$, and $\sigma \vec{E}$, subject to the indek of riskaversion $\gamma$. The estimation of this model is discussed in the next section.

\section{Estimation and Data.}

Eqn. (12) is an exact relation between changes in the price of equity and unanticipated changes in the explanatory variables. If no other variables affected stock prices (and the linearization used to derive (11) and the $A R(1)$ relations were exact), this equation would fit the data perfectly, completely explaining se. This of course is unlikely to be the case. In general there will be other variables affecting stock prices, observed by investors but "hidden" to the econometrician, so that Ee will remain partly unexplained. We can account for these hidden variables by including an additive error term, $v_{t}$, in eqn. (12).

I will make the standard assumption that the price of equity follows a geometric random walk, so that the expectational error $\varepsilon_{t}$ in eqn. (5) is normally distributed, serially uncorrelated, and has a time-varying variance oE. Then the additive error term $v_{t}$ will also be normally distributed and serially uncorrelated, and heteroscedastic with variance roughly proportional to oe. Therefore before estimating eqn. (12) (or eqn. (5)), I divide through by $\sigma_{t}$ so that the transformed errors are homoscedastic.

Equations (9a) - (9d) and the transformed eqn. (12) can be estimated simultaneously, subject to the nonlinear constraints (13a) - (13d). Note 
that all of the constraints depend on the unknown parameter $y$, the index of

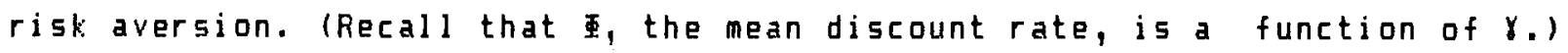
Compared to estimating eqn. (5), this provides a more efficient estimate of $\gamma$ (by utilizing information embodied in the innovations of at, $r_{t}$, etc.), as well as estimates of the elasticities $\eta_{a}, \eta_{r}, \eta_{r}$, and $\eta_{\sigma}$. Also, the underlying theory that relates the elasticities to $\gamma$, the AR(1) parameters, and the tax and financial parameters is completely described by the constraints $(13 a)-(13 d)$, and can be tested by testing these constraints.a

Two issues should be mentioned before proceeding. First, we are treating the RHS variables in eqn. (12) as exogenous, whereas in fact the relationship between the stock market and the macroeconomy is not unidirectional. However, stock prices respond much more quickly to new public information about economic variables $(\alpha, r$, etc.) than those variables respond to stock prices." Also, we are measuring the short-run impact of changes in these variables, i.e. the change in price that equilibrates the demand for equity with a fixed supply, given the change in the expected flow of dividends and/or the discount rate. Thus to good approximation the RHS variables should indeed be viewed as exogenous.

Second, the error term $v_{t}$ includes the effects of unanticipated changes in omitted variables, such as tax rates, world comodity prices, etc. If innovations in omitted variables are correlated with those on the RHS of

Maximum likelihood estimation is used, iterating over the covariance matrix. The test statistic is $2\left(L_{u}-L_{r}\right)$, where $L_{u}$ and $L_{r}$ are the values of the log likelihood function for the unrestricted and restricted models respectively. This is distributed as chi-square, with degrees of freedom equal to the number of restrictions.

-Fischer and Merton (1984), for example, find the stock market to be a good predictor of changes in GNP and its components. 
(12), the parameter estimates could be biased. The use of instrumental variables is not a practical solution because the only effective instruments will be macroeconomic variables which themselves are likely to be correlated with omitted variables. Fortunately this problem is unlikely to be severe, because innovations in any omitted variables will affect stock prices much more rapidly than they affect economic variables.

Estimation of the model is done on both an annual and monthly basis. In each case it requires values for the tax and financial parameters, and data for capital gains and dividends based on an aggregate stock price index $F$, and for the exogenous variables $\alpha, r, \pi$, and $\sigma^{2}$. For estimation on an annual basis I use monthly CRISP data for the total return, the rate of capital gain, and the dividend rate on the NYSE Index. After adjusting for inflation the total return series is used to generate an annual non-overlapping series for the sample variance of the real return in year $t$ :

$$
\sigma_{t}^{2}=(1 / 11) \sum_{j=1}^{2} x_{t, j}^{2}
$$

where $x_{t}, d$ is the logarithaic return in month $j$ of year t.10

Monthly data for the nominal Treasury bill rate and the rate of inflation are used to calculate the real interest rater, and the monthly series for $F, r$, and $\pi$ are annualized. There is no standard source of data for a, but we can draw upon the work of Feldstein, Foterba, and DicksMireaux (1983), who calculated an annual series for the realized pretax rate of profit. This series for $\alpha$ covers the years 1948-1983, and sets the

10This estimate of the sample variance is biased, but only slightly. See Merton (1980). 
limit on the time bounds for estimation. ${ }^{2}$

The model is also estimated with monthly series. Daily data for the total return on the combined NYSE and AMEX index, obtained from the CRISP tape for 1962-1983, are used to generate a monthly non-overlapping series for the sample variance of the nominal return.12 Separate data for capital gains and dividends were unavalable; instead an average dividend rate, computed for 1962-1983 from the monthly returns data, was used to divide the total return into its components.13 I use monthly sums of the daily returns, together with the monthly data for $r$ and $\pi$. A monthly series is calculated for a by regressing the annual series on a set of instruments correlated with profitability, and for which monthly data are available.14

Ideally, changes in the tax and financial parameters should be embodied in eqn. (12). For example, the effective corporate tax rate T. might have been specified as an exogenous variable that also follows an AR(1) process, with innovations in this rate included on the RHS of (12), and with a corresponding cross-equation parameter constraint. In practice, our knowledge of or ability to compute these parameters is too limited to treat

1:The data are from column 4 of Table 2 in Feldstein et. al. (1983). The published data cover the years 1948-1979, but an updated and revised series was provided by James Poterba.

asince there is no daily inflation data, one cannot estimate the sample variance of the real return. The variance of the nominal return is a good approximation, however, in that the rate of inflation usually does not vary much over the course of a month. In computing this monthly series for $\sigma^{2}$, eqn. (14) is adjusted for non-trading days by dividing the daily returns by the square root of the number of days between trades.

1sThis division is necessary only because of the different tax treatment of dividends and capital gains.

14 These include the Index of Net Business Formation, and the rates of change of the Index of Industrial Production, manufacturers unfilled orders, and personal income. 
them as data series. Instead I treat them as fixed, and calculate average values for 1948-1983.2s These values are listed in Table 1, together with the corresponding values for $\phi_{1}, \ldots, \phi_{0}$, the $1948-83$ mean values for $\alpha_{1} r, \pi$, and $\sigma^{2}$, and definitions of all of the symbols used in the paper.

Using these values, and measuring all variables as annual, rates, we obtain a value of .031 for the mean after-tax dividend rate $D$, and $1.018+$ . 015y for the mean discount rate $\mathbf{1}, 50(13 a)$ - (13d) become:

$$
\begin{aligned}
& \eta_{\alpha}=(1.018+.015 \gamma)\left(1.018+.015 \gamma-e_{\alpha}\right) \\
& \eta_{r}=(1.018+.015 \gamma)\left(1.018+.015 \gamma-e_{r}\right) \\
& \eta_{\pi}=(1.018+.015 \gamma)\left(\frac{192}{\left.1.018+.015 \gamma-e_{\pi}\right)}\right. \\
& \eta_{\sigma}=(1.018+.015 \gamma)\left(1.018+.015 \gamma-e_{\sigma}\right)
\end{aligned}
$$

When variables are measured as monthly rates, $D=.00302, \Phi=1.00167+$ $.00124 \gamma$, the numerators of $(15 a)$ - (15d) remain the same, but the denominators are replaced by $(1.00167+.00124 \gamma)\left(1.00167+.00124 \gamma-p_{1}\right)$, where $i=\alpha, r$, $\pi, \sigma$ respectively.

\section{Results.}

Table 2 shows values of $\gamma$ obtained from OLS estimation of eqn. (5). Fiecall that these initial estimates of $\gamma$ are "naive" in that innovations in the explanatory variables are ignored, but they serve as a basis for comparison. For 1949-83, the estimate of $\gamma$ is above 5 . This number is smaller for the 1962-83 subsample, based on either annual or monthly data.

\footnotetext{
15 For an explanation of how these values were obtained, see the Appendix of my 1984 paper (which used averages for 1965-81).
} 
Results of estimating the full model are shown in Table 3 . Observe that for the full 1949-83 sample, the estimate of $\gamma$ is about 3.4, significantly below that obtained from eqn. (5). (The standard error, however, is close to 1 , so we can not rule out a value for as high as 5.$)$ The elasticities with respect to $\alpha, r$, and $a^{2}$ are all significant; only the inflation rate has no significant effect on stock prices. Finally, the likelihood ratio test fails to reject the cross-equation restrictions.

It is useful to examine the magnitudes of the elasticities. The profit rate elasticity $\eta_{\alpha}$ is statistically significant, and a little larger than 2. During the worst post-War recessions drops in a never exceeded .04 or .05 , so that if this elasticity is taken at face value, reduced profitability should have accounted for at most a $10 \%$ decline in stock prices during these periods. While this may seem small, remember that changes in profitability are transitory. The same is true of the real interest rate, and a $4 \%$ increase in that rate should only decrease stock prices by about $6 \%$.

Changes in $\sigma^{2}$ are even more transitory ( $Q_{\sigma}$ is about.23), but the estimated value of $\gamma$ is high enough, and the actual changes in $\sigma^{2}$ have been large enough, so that this variable can explain a significant share of observed movements in stock prices. The estimate of $\eta_{0}$ is about -2.9 . In 1974, for example, $\Delta \sigma^{2}$ was about. 04 , which would account for at 1 east $10 \%$, or about a third, of that year's roughly $30 \%$ decline in the market. The decrease that occured in the profit rate would account for another 4 or $5 \%$.

The remainder of Table 3 shows annual and monthly estimates of the model for 1962-83. The annual estimates show roughly similar values for the elasticities, a lower value for Y lagain a standarderror close to 1), and again failure to reject the restrictions of the model. The lower value of $\gamma$ 
is likely to be peculiar to the short sample; note from Table 2 that oLs estimates of eqn. (5) also yield a smaller value of $\gamma$ for 1962-83 than for 1949-83. Estimation of the model with monthly data again yields a value of $\gamma$ of about 3.4 , but very different values of the elasticities. This reflects a failure of eqns. (9a) - (9d) to capture the evolution of the explanatory variables with monthly data, ${ }^{16}$ and a failure of the linearization; observe that the cross-equation restrictions are strongly rejected.

These results let us draw tentative conclusions about the value of the index of relative risk aversion, and the relative importance of profitibility, interest rates, inflation, and the variance of returns as determinants of stock market behavior. First, the index of risk aversion seems to be much larger than estimates from time-series consumption-based studies would suggest, and is probably in the range of 3 to 4 . Second, changes in profitability, real interest rates, and the variance of equity returns are all significant explanators of stock prices. Changes in variance do not explain as much as my earlier paper (1984) suggests, because those changes are not very persistent (as Poterba and Summers (1985) point out). But they do seem to explain more than any other variable, because they have been large in magnitude, and because the index of risk aversion is large.

\section{Concluding Remark.s.}

The model presented here provides a rather simple description of equity pricing, and its limitations are numerous. Ferhaps the most important is the convenient and fundamental assumption that investors have constant relative

'We would expect the monthly estimate of pi when raised to the 12 th to roughly equal the corresponding annual estimate, but it is much less. 
risk aversion. Recent work by King and Leape (1984), using survey data for over 6000 individual households, strongly rejects the CRRA hypothesis. ${ }^{3}$ Unfortunately it is difficult to construct aggregate asset demand models that can be estimated and tested without making this assumption.

There are other limitations. The model is restricted to two assets, and this may result in an overestimate of $\gamma$. (But while it is natural to add long-term bonds, which bear inflation-specific risk, it is doubtful that investors really juggle their holdings of housing, durable goods, and human capital as interest rates, etc. change.) The AR(1) representation for the explanatory variables is overly simple, and probably does not accurately capture investors' rational expectations regarding future changes. Cone can expand the model so that $\alpha, r, \pi ;$ and $\sigma^{2}$ are jointly described by a firstorder vector autoregression, but this introduces b additional parameters, stretching the explanatory power of the data, and probably still not fully capturing the formation of expectations.) And finally some of the variables may not properly measure what they are intended to measure. For example, $\sigma^{2}$, even if estimated accurately, is a crude measure of investors perceptions of capital risk. (Although Hasbrouck's (1984a) work, using survey data to measure perceived risk, yields results consistent with those reported here. These limitations aside, the model provides an alternative framework. for estimating the degree of risk aversion for investors in the aggregate, and for testing the extent to which "fundamental" economic variables can account for the behavior of the stock market. Also, the empirical results may help to illuminate the debate over the relative roles of profitability,

\footnotetext{
$1>$ Also Morin and Suarez (1983), using Canadian household data, find decreasing relative $r i s k$ aversion when housing is excluded from wealth or treated as riskless, and that risk aversion increases uniformly with age.
} 
$-18-$

risk, and inflation as explanators of the secular movements in the market that have been observed during the past few decades. 
TABLE II SYMBOL DEFINITIONS AND PARAMETER VALUES

Symbol:

d

$\overline{0}$

$r_{t}, \bar{r}$

$\mathrm{R}_{\mathrm{t}}$

$u, \vec{a}$

$\gamma$

$\pi_{t}, \bar{\pi}$

$\sigma_{t}^{2}, \bar{\sigma}^{2}$

$\mathbf{I}$

$\theta$

${ }^{\theta}{ }_{c}$

$\lambda$

$\tau_{\text {e }}$

${ }^{\top} \mathbf{5}$

1

$t_{2}$

3

4

5

$5, s_{b}$

$e_{i}, e_{i 0}$
Definition

Corporate borrowing per unit of capital

Ratio of dividends to net earnings

Mean dividend rate $=3_{3}^{\bar{\alpha}}-\phi_{4} \bar{r}-6_{5} \bar{\pi}$

Actual and mean real interest rates

Nominal interest rate

Actual and mean pretax profit rates

Index of relative risk aversion

Actual and mean rates of inflation

Actual \& mean variances of pretax equity returns

Mean discount rate $=1+\phi_{1} \bar{r}+\left(1-\phi_{1}\right) \bar{\pi}+\gamma_{\phi_{2}} \sigma^{2}$

Personal tax rate on interest and dividends

Effective tax rate on capital gains

Net profit loss from $1 \%$ increase in price level .32

Effective corporate income tax rate

statutory corporate income tax rate

$(1-\theta) /\left(1-\theta_{c}\right)$

$\left[(1-\theta) d+\left(1-\theta_{c}\right)(1-d)\right]^{2} /\left(1-\theta_{c}\right)$

$d\left(1-\tau_{e}\right) /(1-b)$

bd $\left(1-\tau^{2}\right) /(1-b)$

$f_{4}+(\lambda-b) d /(1-b)$

Net real returns on equity and bonds

$A R(1)$ parameters $\pi=.042$ .43 $.4 B$

.74

.75

.33

.08

.11

.26

.43

.031

$\bar{r}=.009$

$=.111$

$\sigma^{2}=.020$

$1.018+.015 \gamma$

.30

.05

eqns. $(1)-(2)$

eqn5. (9a)-(9d)

TABLE 2: ESTIMATION OF EQN. (5)

1949-83

1962-83

1962-83

Monthiy

\begin{tabular}{lccc}
\hline$\gamma$ & 5.145 & 3.660 & 4.038 \\
& $(1.421)$ & $(1.525)$ & $(2.200)$ \\
$R^{2}$ & .091 & .173 & -.017 \\
DW & 2.154 & 2.158 & 1.964 \\
\hline
\end{tabular}


TABLE 3, ESTIMATION OF FULL MODEL

(Standard errors and critical 5\% level of $x^{2}$ in parentheses.)

\begin{tabular}{|c|c|c|c|}
\hline Coeff. & $\begin{array}{c}(1) \\
1949-83\end{array}$ & $\begin{array}{c}(2) \\
1962-83\end{array}$ & $\begin{array}{c}(3) \\
1962-83 \\
\text { (Monthly) }\end{array}$ \\
\hline$\eta_{a}$ & $\begin{array}{c}2.352 \\
(0.641)\end{array}$ & $\begin{array}{l}2.829 \\
(0.981)\end{array}$ & $\begin{array}{l}15.256 \\
(2.675)\end{array}$ \\
\hline$\eta_{r}$ & $\begin{array}{l}-1.407 \\
(0.259)\end{array}$ & $\begin{array}{l}-1.443 \\
(0.332)\end{array}$ & $\begin{array}{l}-4.286 \\
(0.367)\end{array}$ \\
\hline$\eta_{\pi}$ & $\begin{array}{l}.0049 \\
(.1306)\end{array}$ & $\begin{array}{l}.2314 \\
(.1441)\end{array}$ & $\begin{array}{l}.3823 \\
(.2298)\end{array}$ \\
\hline$\eta_{0}$ & $\begin{array}{l}-2.887 \\
(0.721)\end{array}$ & $\begin{array}{l}-2.035 \\
(0.941)\end{array}$ & $\begin{array}{l}-6.464 \\
(1.443)\end{array}$ \\
\hline$\gamma$ & $\begin{array}{c}3.447 \\
(0.937)\end{array}$ & $\begin{array}{c}1.672 \\
(0.863)\end{array}$ & $\begin{array}{c}3.350 \\
(0.744)\end{array}$ \\
\hline${ }^{p} \theta_{\alpha x}$ & $\begin{array}{l}.0237 \\
(.0093)\end{array}$ & $\begin{array}{l}.0086 \\
(.0064)\end{array}$ & $\begin{array}{l}.00034 \\
(.00008)\end{array}$ \\
\hline${ }^{p} \alpha$ & $\begin{array}{l}.7718 \\
(.0808)\end{array}$ & $\begin{array}{l}.8853 \\
(.0566)\end{array}$ & $\begin{array}{l}.9592 \\
(.0091)\end{array}$ \\
\hline Por & $\begin{array}{l}.0026 \\
(.0027)\end{array}$ & $\begin{array}{l}.0013 \\
(.0021)\end{array}$ & $\begin{array}{l}.00012 \\
(.00016)\end{array}$ \\
\hline${ }^{P} r$ & $\begin{array}{l}.4617 \\
(.1120)\end{array}$ & $\begin{array}{l}.4802 \\
(.1293)\end{array}$ & $\begin{array}{l}.7967 \\
(.0163)\end{array}$ \\
\hline$P_{0 \pi}$ & $\begin{array}{l}.0142 \\
(.0054)\end{array}$ & $\begin{array}{l}.0243 \\
(.0109)\end{array}$ & $\begin{array}{l}.00068 \\
(.00018)\end{array}$ \\
\hline$P$ & $\begin{array}{l}.6935 \\
(.0810)\end{array}$ & $\begin{array}{l}.6232 \\
(.1435)\end{array}$ & $\begin{array}{l}.8595 \\
(.0168)\end{array}$ \\
\hline${ }^{0} 0 \sigma$ & $\begin{array}{l}.0157 \\
(.0034)\end{array}$ & $\begin{array}{l}.0133 \\
(.0047)\end{array}$ & $\begin{array}{l}.00040 \\
(.00007)\end{array}$ \\
\hline$e_{\sigma}$ & $\begin{array}{l}.2325 \\
(.1315)\end{array}$ & $\begin{array}{l}.4522 \\
(.1310)\end{array}$ & $\begin{array}{l}.6194 \\
(.0473)\end{array}$ \\
\hline$x^{2}$ & $\begin{array}{l}5.162 \\
(9.49)\end{array}$ & $\begin{array}{l}8.108 \\
(9.49)\end{array}$ & $\begin{array}{l}32.36 \\
(9.49)\end{array}$ \\
\hline
\end{tabular}




\section{REFERENCES}

Black, Fischer, "Studies of Stock Price Volatility Changes," Proceedings of the 1976 Meetings of the American Statistical Association. Business and Economic Statistics Section, 177-181.

Bodie, Zvi, Alex Kane, and Robert MeDonald, "Why Are Real Interest Rates So High," NBER Working Paper No. 1141, June 1983.

Chen, Nai-Fu, Richard Roll, and Stephen A. Ross, "Economic Forces and the Stock Market: Testing the APT and Alternative Asset Pricing Theories," unpublished, 1985.

Feldstein, Martin, "Inflation and the Stock Market," American Economic Review, December 1980, 70, 839-47.

Feldstein, Martin, "Inflation, Tax Rules, and the Stock Market," Journal of Monetary Economic5, July 1980, b, 309-31.

Feldstein, Martin, James Poterba, and Louis Dicks-Mireaux, "The Effective Tax Rate and the Pretax Rate of Return," Journal of Public Economics, March 1983, 211, 129-158.

Fischer, Stanley, and Robert C. Merton, "Macroeconomics and Finance: The Role of the Stock Market," NBER Working Paper No. 1291, March 1984.

Frankel, Jeffrey A., "A Test of Portfolio Crowding-Out and Related Issues in Finance," NBER Working Paper No. 1205, September 1983.

French, Kenneth R., G. William Schwert, and Robert F. Stambaugh, "Expected Stock Returns and Volatility," University of Rochester, Graduate School of Management, Working Paper No. MERC 85-10, November 1985.

Friedman, Benjamin M., "Crowding Out or Crowding In? Evidence on Debt-Equity Substitutability," NBER Working Paper No. 1565, February 1985.

Friend, Irwin, and Marshall E. Blume, "The Demand for Risky Assets," American Economic Review, December 1975, 65, 900-923.

Friend, Irwin, and Joel Hasbrouck, "Effect of Inflation on the Profitability and Valuation of U.S. Corporations," in M. Sarnat and G. Szego, eds., Savings, Investment, and Capital Markets in an Inflationary Economy, Ballinger, 1982.

Gordon, Myron J., "The Impact of Real Factors and Inflation on the Performance of the U.S. Stock Market From 1960 to 1980, "Journal of Finance, May $1983,38,553-563$.

Grossman, Sanford J., and Robert J. Shiller, "The Determinants of the Variability of Stock Market Prices," American Economic Review, May $1981,71,222-27$. 
Hasbrouck, Joel, "Stock Returns, Inflation and Economic Activity: The Survey Evidence," Journal of Finance, 1984, 39,

Hasbrouck, Joel, "Ex Ante Uncertainty and Ex Post Variance in Linear Return Models: An Econometric Analysis," unpublished, March 1984.

Hansen, Lars Peter, and Kenneth J. Singleton, "Stochastic Consumption, Risk Aversion and the Temporal Behavior of Stock Returns," Journal of Folitical Economy, April 1983, 91, 249-65.

Hendershott, Patric H., "Expectations, Surprises, and Treasury Bill Rates: 1960-82," Journal of Finance, July 1984, 39, 685-696.

King, Mervyn A., and Jonathan I. Leape, "Wealth and Portfolio Composition: Theory and Evidence," NBER Working Paper No. 1468, September 1984.

Mankiw, N.. Gregory, Julio J. Rotemberg, and Lawrence H. Summers, "Intertemporal Substitution in Macroeconomics," Quarterly Journal of Economics, February 1985.

Merton, Robert C., "An Intertemporal Capital Aset Pricing Model," Econometrica, September 1973, 141, 867-887.

Merton, Robert C., "On Estimating the Expected Return on the Market: An Exploratory Investigation," Journal of Financial Economics, 1980, 旦, $323-361$.

Modigliani, Franco, and Richard Cohn, "Inflation, Rational Valuation, and the Market," Financial Analysts Journal, March 1979, 35, 3-23.

Morin, Roger A., and A. Fernandez Suarez, "Risk Aversion Revisited," Journal of Finance, September 1985, 3B, 1201-16.

Officer, R., "The Variability of the Market Factor of the New York Stock Exchange," Journal of Business, 1973, 46, 434-457.

Pindyck, Robert S., "Risk, Inflation, and the Stock Market," American Economic Review, June $1984,74,335-351$.

Poterba, James M., and Lawrence H. Summers, "The Persistence of Volatility and stock Market Fluctuations," NBER Working Paper No, 1462, April 1985. 